\title{
Iron Sucrose Promotes Endothelial Injury and Dysfunction and Monocyte Adhesion/Infiltration
}

\author{
Vaijinath S. Kamanna ${ }^{\text {a, b }}$ Shobha H. Ganji ${ }^{a}$ b Stanislav Shelkovnikov ${ }^{a}$ \\ Keith Norris ${ }^{c}$ Nosratola D. Vaziria

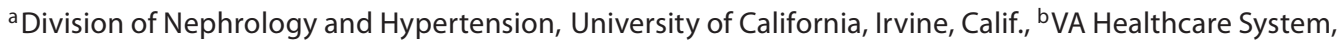 \\ Long Beach, Calif., and ' Department of Internal Medicine, Charles Drew University, Los Angeles, Calif., USA
}

\section{Key Words}

Iron sucrose - Endothelial function - Atherosclerosis •

End-stage renal disease $\cdot$ Cardiovascular disease $\cdot$

Oxidative stress

\begin{abstract}
Background/Aims: Intravenous (IV) iron preparations are widely used in the management of anemia in ESRD populations. Recent changes in reimbursement policy have dramatically increased the use of IV iron to lower the use of costly erythropoiesis-stimulating agents. These preparations are frequently administered with insufficient attention to the total body iron stores or presence of inflammation which is aggravated by excess iron. Endothelial injury and dysfunction are critical steps in atherosclerosis, thrombosis and cardiovascular disease. IV iron preparations raise plasma nontransferrin-bound iron which can promote oxidative stress, endothelial damage and dysfunction. We explored the effect of an IV iron preparation on endothelial cells, monocytes and isolated arteries. Methods: Primary cultures of human aortic endothelial cells (HAEC) were treated with pharmacologically relevant concentrations of iron sucrose (10-100 $\mu \mathrm{g} /$ $\mathrm{ml}$ ) for 4-24 h. Endothelial cell morphology, viability, and monocyte adhesion were tested. Endothelial function was
\end{abstract}

assessed by measuring the vasorelaxation response to acetylcholine in normal rat thoracic aorta rings preincubated with iron sucrose $(200 \mu \mathrm{g} / \mathrm{ml})$. Results: In contrast to the control HAEC which showed normal cobblestone appearance, cells treated with iron sucrose (50-100 $\mu \mathrm{g} / \mathrm{ml}$ ) for $4 \mathrm{~h}$ showed loss of normal morphological characteristics, cellular fragmentation, shrinkage, detachment, monolayer disruption and nuclear condensation/fragmentation features signifying apoptosis. HAEC exposure to iron sucrose (10-100 $\mu \mathrm{g} / \mathrm{ml})$ increased monocyte adhesion 5- to 25-fold. Incubation in media containing $200 \mu \mathrm{g} / \mathrm{ml}$ iron sucrose for $3 \mathrm{~h}$ caused marked reduction in the acetylcholine-mediated relaxation in phenylephrine-precontracted rat aorta. Conclusion: Pharmacologically relevant concentration of iron sucrose results in endothelial injury and dysfunction and marked increase in monocyte adhesion.

Copyright $\odot 2011$ S. Karger AG, Basel

\section{Introduction}

Accelerated atherosclerosis and cardiovascular disease are the main cause of premature death in the ESRD population. Endothelial injury and dysfunction are critical steps in the pathogenesis of atherosclerosis, thrombo-

\section{KARGER}

Fax +41613061234 E-Mail karger@karger.ch www.karger.com
(C) 2011 S. Karger AG, Basel

0250-8095/12/0352-0114\$38.00/0

Accessible online at:

www.karger.com/ajn
Vaijinath S. Kamanna, PhD

Medical Research Service (09-151), VA Healthcare System

5901 E. 7 th Street

Long Beach, CA 90822 (USA)

Tel. +1 562826 5820, E-Mail Vaijinath.kamanna@va.gov 
sis and cardiovascular disease. There is mounting evidence supporting the role of iron in the pathogenesis of endothelial dysfunction and atherosclerosis. First, iron content of macrophages is markedly elevated in the atherosclerotic lesions [1, 2]; second, increased body iron store is associated with the risk of cardiovascular events [3]; third, iron depletion reduces atherosclerotic plaque formation in apoE-deficient mice [3, 4]; fourth, in humans blood donation lowers the risk of myocardial infarction [5]; fifth, phlebotomy slows progression of peripheral vascular disease [6], and sixth, iron chelation therapy improves endothelial function in patients with coronary artery disease [7].

The adverse cardiovascular effects of the catalytically active iron are primarily due to its ability to cause oxidative stress which in turn results in insulin resistance [8], antioxidant depletion, LDL oxidation [9], endothelial injury and dysfunction [7], macrophage activation and foam cell transformation [10] and thrombus formation [11].

Intravenous iron (IV Fe) preparations are widely used in the management of anemia in ESRD populations. With implementation of bundling reimbursement policy, the use of these agents in ESRD patients has dramatically increased. This approach has been adopted by dialysis facilities in an attempt to reduce the cost of anemia treatment by limiting the use of more costly erythropoiesis-stimulating agents. In many instances, IV iron preparations are administered on a routine basis with insufficient attention to the total body iron stores or presence and severity of inflammation, which is a constant feature of advanced CKD. Non-transferrin-bound iron can avidly promote oxidative stress which as noted above is a major mediator of endothelial damage and dysfunction.

The present study was designed to examine the effect of pharmacologically relevant concentrations of one of the commonly used IV iron preparations on cultured human aorta endothelial cells, macrophages, endothelialmacrophage interactions and the endothelium-mediated vasorelaxation in normal rat aorta.

\section{Methods}

Cells, Drugs, and Chemicals

Primary cultures of normal human aortic endothelial cells (HAEC) and HAEC growth media were obtained from Lonza (Walkersville, Md., USA). Human monocytic/macrophage THP1 cell line was purchased from American Type Culture Collection (Rockville, Md., USA). Acetylcholine iodide, phenylephrine, and D-glucose were purchased from Sigma Chemical Co. (St. Louis,
Mo., USA). Iron sucrose (100 mg/ml) was purchased from American Regent, Inc. (Shirley, N.Y., USA).

\section{Cultured Endothelial Cells and Treatment}

Primary cultures of normal HAEC were grown to confluence in EBM-2 growth media (4-6 passages, in 6-well plates) and incubated in the absence (control) or presence of iron sucrose (10-100 $\mu \mathrm{g} / \mathrm{ml}$ ) for 4 or $24 \mathrm{~h}$ at $37^{\circ} \mathrm{C}$. Morphological changes in HAEC were examined by phase contrast microscopy using Nikon Eclipse 300 inverted microscope ( $\times 20$ magnification). Cell viability was tested by a cell growth determination kit using 3-[4,5-dimethylthiozol-2-yl]-2,5-diphenyl tetrazolium bromide (Sigma). Formation of MTT formazan crystals by viable cell mitochondrial dehydrogenases (an index of cell viability) was determined by measuring the optical density at $570 \mathrm{~nm}$ with an ELISA Reader (Molecular Devices).

In in vitro studies with endothelial cells, we used iron sucrose at $10-100 \mu \mathrm{g} / \mathrm{ml}$ concentrations added in the culture media. The rationale for the choice of these concentrations was based on the anticipated plasma levels following administration of the approved doses of this drug (100 mg in hemodialysis patients and $300 \mathrm{mg}$ IV in PD patients) considering the blood volume of about 51 of which $60-70 \%$ in plasma where the drug is distributed. Given the large size of the iron complex, the distribution of the product is largely limited to plasma.

\section{Monocyte Adhesion to HAEC}

Human monocytic cell line (THP-1) was labeled with fluorescent dye by incubating with 2',7'-bis(2-carboxyethyl)-5,6-carboxy fluorescein acetoxymethyl ester $(10 \mu \mathrm{g} / \mathrm{ml})$ for $1 \mathrm{~h}$. HAEC were preincubated with iron sucrose $(10-100 \mu \mathrm{g} / \mathrm{ml})$ for $4 \mathrm{~h}$. Fluorescently labeled THP-1 cells were added to HAEC monolayers, and incubated for $1 \mathrm{~h}$. Nonadherent THP-1 cells were removed by washing with PBS containing 1\% FBS. Adhered monocytes were dissolved in $0.1 \%$ SDS, and the fluorescence intensity was measured with excitation and emission of $485 / 562 \mathrm{~nm}$.

\section{Animals}

Fifteen male Sprague-Dawley rats (Harlan) weighing 250$300 \mathrm{~g}$ were purchased and housed in an AAALAC approved facility with a standard 12-hour day-night cycle (University of California, Irvine, Calif., USA). All procedures were approved by the University of California Irvine Institutional Animal Care and Use Committee. After anesthesia by ketamine, the animals were sacrificed by exsanguinations via cardiac puncture. Thoracic aorta was removed immediately.

Thoracic Aorta Preparation

Thoracic aorta between the aortic arch and diaphragm was dissected and placed in cold Krebs bicarbonate solution bubbled with $95 \% \mathrm{O}_{2}$ and $5 \% \mathrm{CO}_{2}$ and consisted of (in $\mathrm{mM}$ ): $\mathrm{NaCl}, 118 ; \mathrm{KCl}$, 4.7; $\mathrm{CaCl}_{2}, 2.5 ; \mathrm{MgSO}_{4}, 1.6 ; \mathrm{KH}_{2} \mathrm{PO}_{4}, 1.2 ; \mathrm{NaHCO}_{3}, 24 ;$ D-glucose, 10. Tissues were cleaned to remove adipose adhering to the adventitia. The aortas were then sectioned into transverse rings of $3 \mathrm{~mm}$ in width.

\section{Tension Registration}

The aortic rings were carefully mounted between two triangles of 28-gauge stainless steel. The rings were then vertically placed in an organ bath containing $10 \mathrm{ml}$ of Krebs solution, heat- 

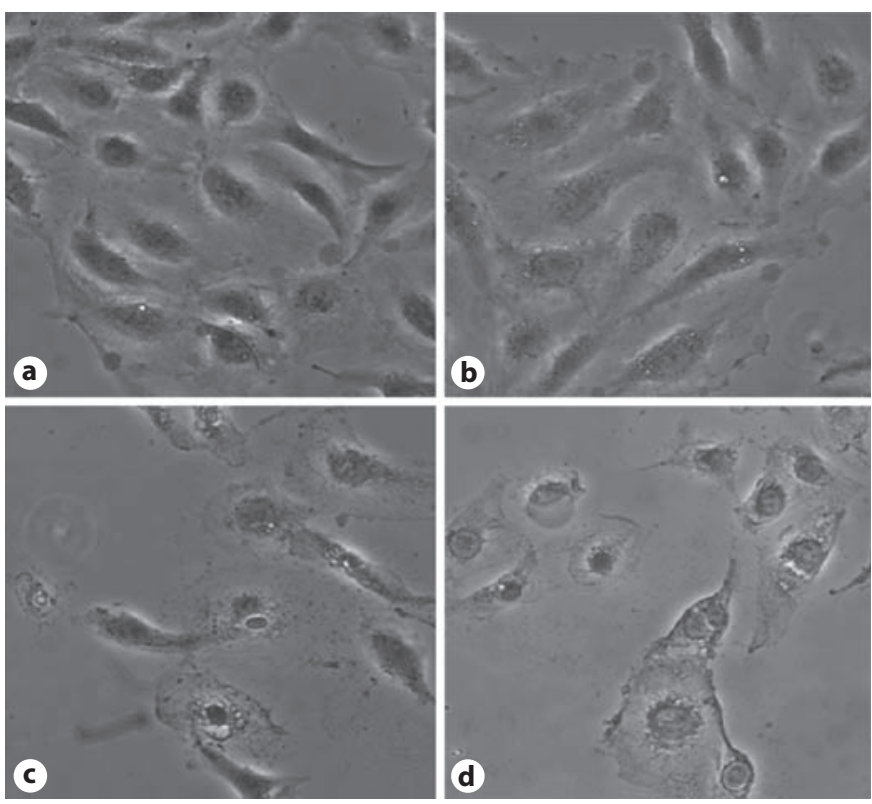

Fig. 1. Effect of iron sucrose on cellular morphology: HAEC were grown in 6-well plates in EBM-2 growth media for 2 days to attain about $80 \%$ confluency. Cells were treated with various concentrations of iron sucrose $(10-100 \mu \mathrm{g} / \mathrm{ml})$ for $4 \mathrm{~h}$. Morphological changes in HAEC were examined by phase contrast microscopy using Nikon Eclipse 300 inverted microscope ( $\times 20$ magnification). a Control. b $10 \mu \mathrm{g} / \mathrm{ml}$ iron sucrose. c $50 \mu \mathrm{g} / \mathrm{ml}$ iron sucrose. d $100 \mu \mathrm{g} / \mathrm{ml}$ iron sucrose.

ed to $37^{\circ} \mathrm{C}$, and bubbled with $\mathrm{O}_{2}$ and $\mathrm{CO}_{2}$. One of the two triangles was attached to a post in the tissue bath and the other to a Fort 10 isometric force transducer (World Precision Instruments, Sarasota, Fla., USA) for recording of changes in isometric tension. Transducer was connected to a TMB-4 amplifier transbridge (World Precision Instruments) which was itself attached to a MacLab digital to analog converter (AD Instruments, Colorado Springs, Colo., USA) which converted tension to a tracing on a computer screen. The aortic rings were then slowly stretched using a micrometer. The tissue was allowed to equilibrate in the bath for $2 \mathrm{~h}$, while a constant tension of $1 \mathrm{~g}$ was maintained. In preliminary experiments, we found that a 1-2-3 g resting stretch for $2 \mathrm{~h}$ provides optimal condition for subsequent induction of maximal contraction. After $2 \mathrm{~h}$, arterial rings hold contraction upon stimulation with either $\mathrm{PhE}(10 \mu \mathrm{M})$ or $\mathrm{KCl}(80 \mathrm{mM})$ for a minimum of $45 \mathrm{~min}$, which is well under the time required for the experiments.

\section{Concentration-Response Curves}

All concentration-response curves were obtained by the cumulative addition of select compounds, allowing the force to reach steady-state before the addition of the next concentration. Drugs were added to the organ bath in volumes from 1 to $100 \mu \mathrm{l}$. Contractile effect of potassium was measured in the beginning of each experiment. In experiments with $\mathrm{KCl}(6-80 \mathrm{mM})$, the $\mathrm{NaCl}$ concentration was reduced accordingly in order to maintain con- stant osmolarity. Then, tissues were washed twice with fresh Krebs solution, allowed to equilibrate back to baseline for $90 \mathrm{~min}$, and then PhE concentration-response curves were obtained. Subsequently, the tissues were washed six times with fresh Krebs, and again allowed to re-equilibrate for $90 \mathrm{~min}$. Relaxation response to acetylcholine was determined after precontraction with $1 \mu \mathrm{M}$ phenylephrine, which evokes maximal contraction. Phenylephrine contraction alone was found to be stable for at least the 40 min in which the studies were completed. Iron sucrose was added at a concentration of $200 \mu \mathrm{g} / \mathrm{ml}$ to the bath containing the aorta rings $4 \mathrm{~h}$ before the study. Maximal effect and the concentrations causing $50 \%$ of maximal response were used as the measure of sensitivity.

\section{Statistical Analysis}

All values are reported as means and standard error of the mean (SEM); they were calculated using the PRIZM v4 program (GraphPad Software, San Diego, Calif., USA). Statistical comparisons between data groups were performed using paired Student's $t$ test. For all statistical tests, $\mathrm{p}<0.05$ level of confidence was accepted for statistical significance.

\section{Results}

\section{Effect of Iron Sucrose on Cultured Endothelial Cells}

As shown by phase-contrast microscopy, control HAEC showed normal morphology with typical cobblestone appearance (fig. 1a). However, cells treated with iron sucrose (50 and $100 \mu \mathrm{g} / \mathrm{ml}$ ) for $4 \mathrm{~h}$ lost normal morphological characteristics and showed the presence of cellular fragmentation and debris (fig. 1c, d). Many of the cells shrunk and detached from the plates, and the monolayer was disrupted in cells treated with iron sucrose at 50 and $100 \mu \mathrm{g} / \mathrm{ml}$ (fig. 1c, d). Additionally, many cells treated with iron sucrose at 50 and $100 \mu \mathrm{g} / \mathrm{ml}$ exhibited typical features of apoptosis including condensed and/or fragmented nuclei when compared to control cells (fig. 1c and d vs. a). Although cells treated with lower concentrations of iron sucrose $(10 \mu \mathrm{g} / \mathrm{ml})$ showed relatively normal gross morphology at $4 \mathrm{~h}$, there were subtle and early signs of alterations in cellular morphology including cellular swelling (fig. 1b). Moreover, treatment with iron sucrose as low as $10 \mu \mathrm{g} / \mathrm{ml}$ for $24 \mathrm{~h}$ resulted in considerable morphological changes and appearance of early cellular fragments and debris in cultured endothelial cells. Treatment at $50-100 \mu \mathrm{g} / \mathrm{ml}$ for $24 \mathrm{~h}$ showed much higher alterations in cellular morphology as compared to 4 -hour treatment (data not shown).

Additional studies were performed to directly determine the effect of iron sucrose on cellular viability and/ or cytotoxicity by assessing mitochondrial dehydrogenase activity using MTT assay kit. Increased formation of 


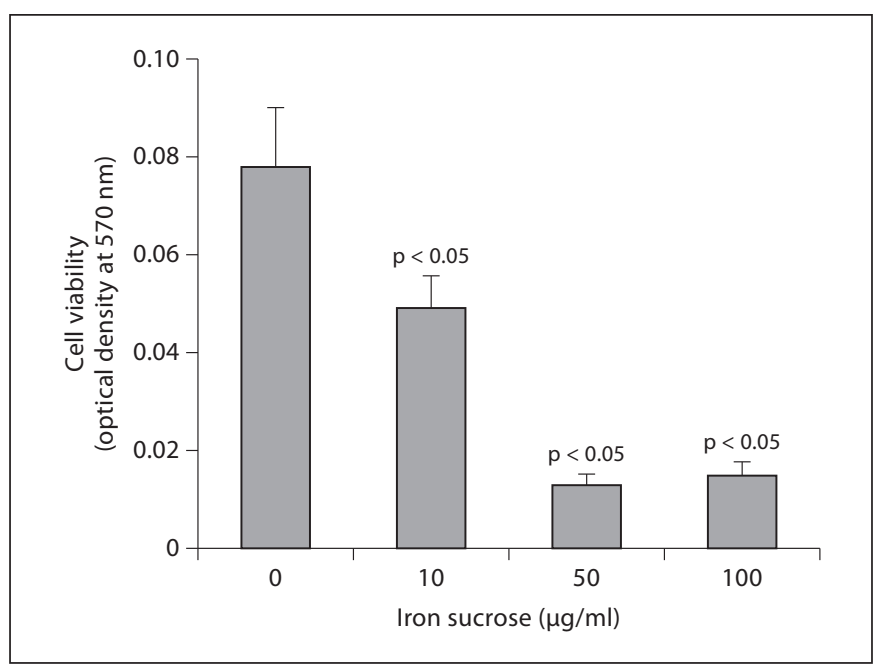

Fig. 2. Effect of iron sucrose on cell viability. HAEC were grown in 12-well plates for 2 days to attain about $80 \%$ confluency in EBM-2 growth media. Cells were treated with iron sucrose $(0-100$ $\mu \mathrm{g} / \mathrm{ml}$ ) for $24 \mathrm{~h}$. Cellular viability was measured by MTT assay kit as described in 'Methods'. Data presented are mean of 3 separate experiments.

MTT formazan purple crystals by viable cell mitochondrial dehydrogenase represents increased number of viable cells. As shown in figure 2, iron sucrose (10-100 $\mu \mathrm{g} /$ $\mathrm{ml}$ ) dose-dependently decreased cellular viability. Iron sucrose at 50 and $100 \mu \mathrm{g} / \mathrm{ml}$ concentrations caused severe cellular toxicity as only about $20 \%$ cells were viable.

\section{Effect of Iron Sucrose on Monocyte-Endothelial}

\section{Interaction}

We further examined the impact of iron sucrose-mediated endothelial cell injury on monocyte adhesion, one of the key early pathobiological events involved in endothelial dysfunction and atherosclerosis. Treatment of HAEC with iron sucrose at concentration as low as $10 \mu \mathrm{g} /$ $\mathrm{ml}$ for $4 \mathrm{~h}$, markedly increased monocyte adhesion 5 -fold (fig. 3). At 50 and $100 \mu \mathrm{g} / \mathrm{ml}$, iron sucrose robustly induced monocyte adhesion 25 -fold as compared to controls (fig. 3).

\section{Effect of Iron Sucrose on Endothelial Function}

Cumulative concentration-response curve in the phenylephrine $(1 \mu \mathrm{M})$-precontracted endothelium-intact rat thoracic aorta rings showed a marked reduction in acetylcholine-mediated relaxation by iron sucrose (fig. 4a). In fact, preincubation in media containing iron sucrose lowered the maximum relaxation response to

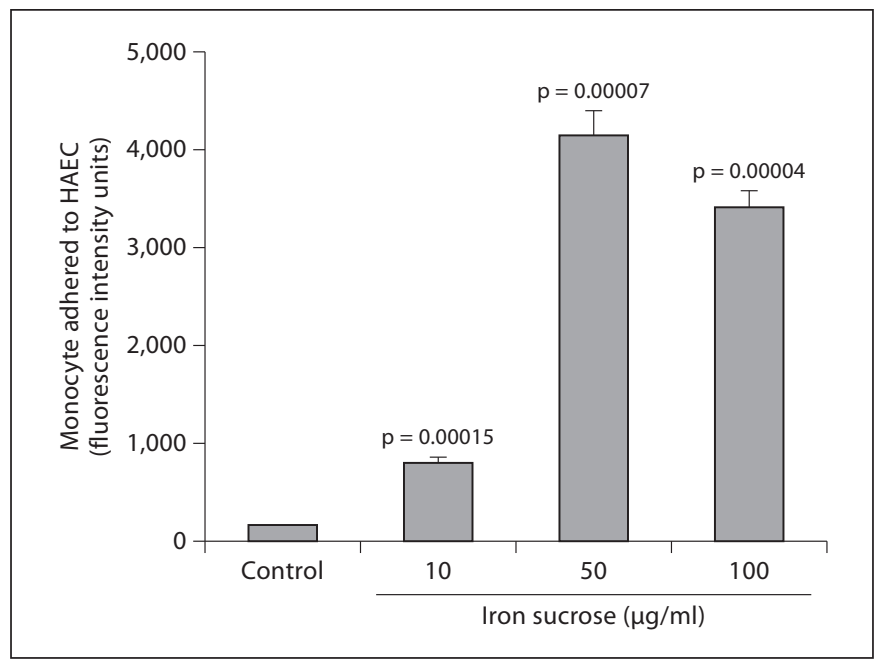

Fig. 3. Effect of iron sucrose on monocyte adhesion to endothelial cells. HAEC were treated with iron sucrose $(10-100 \mu \mathrm{g} / \mathrm{ml})$ for $4 \mathrm{~h}$. Fluorescently labeled monocytic THP-1 cells were added to the HAEC. After $1 \mathrm{~h}$, monocyte adhesion to HAEC was assessed by measuring fluorescence intensity. Data are mean of 3 separate experiments.

acetylcholine by greater than $50 \%$ (fig. $4 \mathrm{~b}$ ). These findings point to the induction of endothelial dysfunction by iron sucrose. The observed endothelial dysfunction in iron sucrose-exposed artery rings represents the functional counterpart of the injury seen in the cultured endothelial cells.

\section{Discussion}

The present study revealed that iron sucrose, a commonly used IV iron preparation, causes a significant dose- and time-dependent injury in cultured human endothelial cells and promotes endothelial dysfunction as evidenced by marked reduction in acetylcholine-induced relaxation in the arterial tissue. In addition, exposure to the IV iron preparation resulted in a marked increase in monocyte adhesion to the cultured endothelial monolayer simulating arterial wall in vitro, events that are central to the pathogenesis of atherosclerosis. Although these in vitro studies provide evidence for the deleterious effects of iron sucrose on endothelial cell structure and function, caution should be exercised in extrapolation of the findings to the clinical setting.

Mechanistically, by catalyzing the Fenton reaction, iron converts hydrogen peroxide, a relatively innocuous 

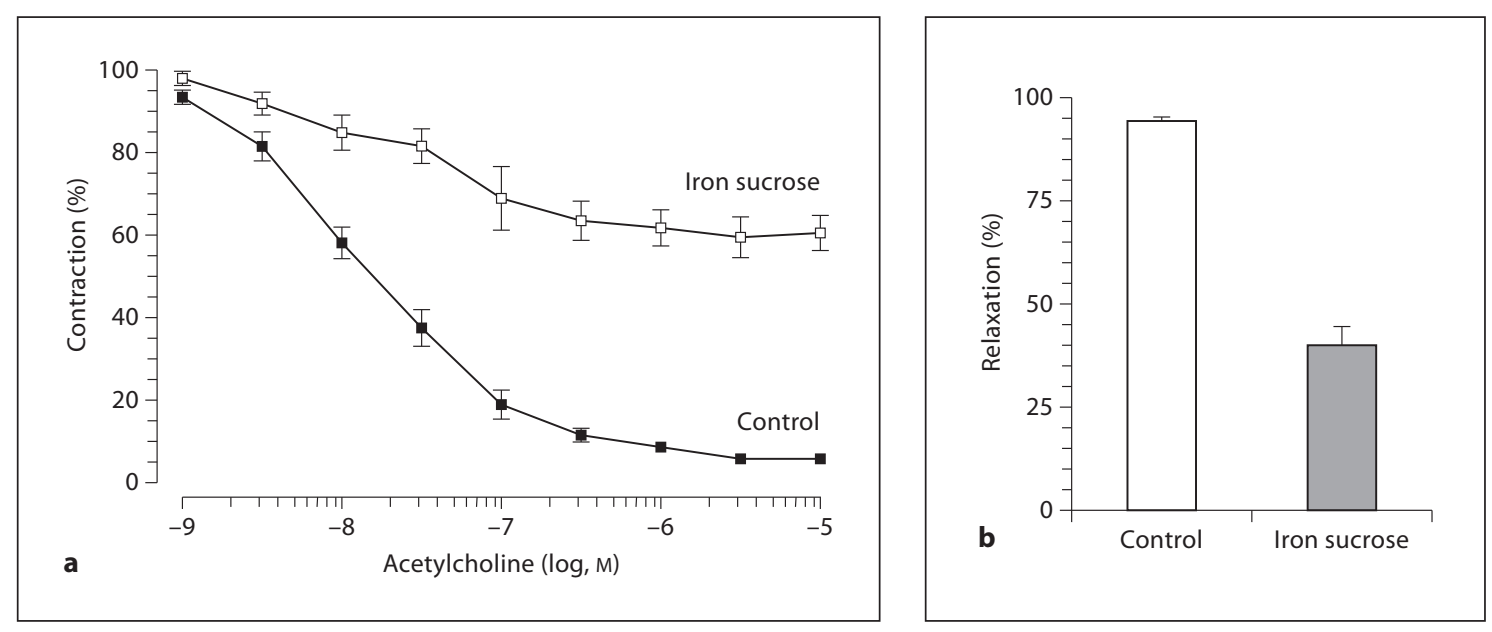

Fig. 4. a Effect of iron sucrose on acetylcholine-induced relaxation in rat thoracic aorta ring. Cumulative concentration-response curves of acetylcholine in control and after 4-hour preincubation with venofer $(200 \mu \mathrm{g} / \mathrm{l})$ was performed on $1 \mu \mathrm{M}$ phenylephrineprecontracted aorta. The contraction obtained after phenylephrine is set as $100 \%$. Values are the mean \pm SE of rings prepared from 6 rats. $\mathbf{b}$ Effect of iron sucrose on rat aorta relaxation by acetylcholine. Maximal relaxing effect of acetylcholine $(10 \mu \mathrm{M})$ in control and after 4-hour preincubation with iron sucrose $(200$ $\mu \mathrm{g} / \mathrm{l})$ was performed on $1 \mu \mathrm{M}$ phenylephrine-precontracted aorta rings. Values are the means \pm SE of 6 rats. and easily containable reactive oxygen species (ROS), to hydroxyl radical $(\cdot \mathrm{OH})$ which is the most reactive and cytotoxic ROS known $\left(\mathrm{H}_{2} \mathrm{O}_{2}+\mathrm{Fe}^{2+} \rightarrow \cdot \mathrm{OH}+\mathrm{OH}^{-}+\right.$ $\mathrm{Fe}^{3+}$ ). The participation of iron in oxidative reaction is perpetuated by subsequent conversion of iron from the ferric to the ferrous state in the presence of endogenous superoxide $\left(\mathrm{O}_{2}^{-}\right)$via the Haber-Weiss reaction $\left(\mathrm{Fe}^{3+}+\mathrm{O}_{2}^{-}\right.$ $\rightarrow \mathrm{Fe}^{2+}+\mathrm{O}_{2}$ ), or by reducing agents such as vitamin $\mathrm{C}$. Iron-induced oxidative stress plays an important part in the pathogenesis of endothelial injury and dysfunction. Administration of IV iron preparations, particularly when used indiscriminately, increases the plasma level of catalytically active, non-transferrin bound labile iron which is capable of causing oxidative stress [12]. In fact, several studies have documented the ability of IV iron preparations to cause oxidative stress in dialysis patients and in experimental animals [13-17]. Oxidative stress, in turn, results in endothelial damage and dysfunction and triggers inflammation via activation of NF- $\kappa \mathrm{B}$, a redoxsensitive transcription factor, which is a master regulator of numerous proinflammatory cytokines and chemokines. The constellation of endothelial damage and dysfunction, heightened monocyte adhesion in response to the IV iron preparation used in this study is consistent with the iron-induced oxidative stress. These conclusions are supported by several clinical and experimental studies. For instance, IV iron preparations (particularly iron sucrose) have been shown to inhibit proliferation and promote apoptosis in cultured endothelial cells [18]. Infusion of iron sucrose in healthy subjects has been reported to raise plasma non-transferrin-bound iron, significantly increase ROS production and acutely impair endothelium-dependent flow-mediated vasodilation induced by brachial artery occlusion [19]. Moreover, IV iron infusion in hemodialysis patients has been shown to significantly increase plasma lipid peroxidation products and induce monocyte IL-8 expression, events which could be partially attenuated by addition of $\mathrm{N}$-acetylcysteine [20]. Finally, cross-sectional studies have shown an association between carotid artery media thickness and the cumulative dose of IV iron and plasma ferritin level in hemodialysis patients [21].

As noted above, via activation of NF- $\kappa \mathrm{B}$, oxidative stress can trigger inflammation. Therefore, IV iron preparations, particularly when used without extreme caution, can promote inflammation. In fact, injection of iron sucrose or iron gluconate in mice has been shown to significantly increase plasma and tissue (liver, renal, and lung) MCP-1, a major proinflammatory mediator, for at least $24 \mathrm{~h}$ [22]. Likewise, infusion of iron sucrose has been shown to result in a transient but significant increase in plasma MCP-1 level in patients with CKD. Repeat IV iron infusion one week later resulted in a lower peak but a more persistent elevation of plasma MCP-1 level [13]. Fi- 
nally, intravenously administered iron has been shown to be taken up by circulating monocytes leading to increase in their iron content and acute activation of the NF- $\mathrm{\kappa B}$ pathway [23]. Elevation of hepcidin with iron overload contributes to accumulation of iron in the monocytes and macrophages. Accumulation of excess iron results in their transformation to the highly proinflammatory M1 macrophage population as shown in humans and experimental animals [24]. Together, these observations provide compelling evidence for the critical role of iron in the pathogenesis of atherosclerosis and cardiovascular disease [25]

In conclusion, the results of the present investigation build upon previous studies, and provide compelling ev- idence for the potential adverse cardiovascular effects of the indiscriminate use of the IV iron preparations in the highly vulnerable patients with advanced CKD.

\section{Acknowledgements}

This project was in part funded by the NIH grants RR026138 and MD000182 (PI, Dr. Keith Norris). The authors wish to thank Mr. Neil Hoa (VA Long Beach) for assisting in phase contrast microscopy.

\section{Disclosure Statement}

Authors do not have any conflict of interest.

\section{References}

$\checkmark 1$ Lapenna D, Pierdomenico SD, Ciofani G, Ucchino S, Neri M, Giamberardino MA, Cuccurullo F: Association of body iron stores with low molecular weight iron and oxidant damage of human atherosclerotic plaques. Free Radic Biol Med 2007;42:492498.

-2 Nagy E, Eaton JW, Jeney V, Soares MP, Varga Z, Galajda Z, Szentmiklosi J, Mehes G, Csonka T, Smith A, Vercellotti GM, Balla G, Balla $\mathrm{J}$ : Red cells, hemoglobin, heme, iron, and atherogenesis. Arterioscler Thromb Vasc Biol 2010;30:1347-1353.

-3 Sullivan JL: Macrophage iron, hepcidin, and atherosclerotic plaque stability. Exp Biol Med (Maywood) 2007;232:1014-1020.

$\checkmark 4$ Lee TS, Shiao MS, Pan CC, Chau LY: Irondeficient diet reduces atherosclerotic lesions in apoE-deficient mice. Circulation 1999;99: 1222-1229.

5 Salonen JT, Tuomainen TP, Salonen R, Lakka TA, Nyyssonen K: Donation of blood is associated with reduced risk of myocardial infarction. The Kuopio Ischaemic Heart Disease Risk Factor Study. Am J Epidemiol 1998; 148:445-451.

-6 Zacharski LR, Chow BK, Howes PS, Shamayeva G, Baron JA, Dalman RL, Malenka DJ, Ozaki CK, Lavori PW: Reduction of iron stores and cardiovascular outcomes in patients with peripheral arterial disease: a randomized controlled trial. JAMA 2007; 297:603-610.

7 Duffy S, Biegelsen E, Holbrook M, et al: Iron chelation improves endothelial cell function in patients with coronary artery disease. Circulation 2001;103:2799-2804

-8 Dongiovanni P, Valenti L, Ludovica FA, Gatti S, Cairo G, Fargion S: Iron depletion by deferoxamine up-regulates glucose uptake and insulin signaling in hepatoma cells and in rat liver. Am J Pathol 2008;172:738-747.
9 Valenti L, Valenti G, Como G, Burdick L, Santorelli G, Dongiovanni P, Rametta R, Bamonti F, Novembrino C, Fracanzani AL, Messa PG, Fargion S: HFE gene mutations and oxidative stress influence serum ferritin, associated with vascular damage, in hemodialysis patients. Am J Nephrol 2007;27:101107.

10 Kraml PJ, Klein RL, Huang Y, Nareika A, Lopes-Virella MF: Iron loading increases cholesterol accumulation and macrophage scavenger receptor I expression in THP-1 mononuclear phagocytes. Metabolism 2005; 54:453-459.

11 Day SM, Duquaine D, Mundada LV, Menon RG, Khan BV, Rajagopalan S, Fay WP: Chronic iron administration increases vascular oxidative stress and accelerates arterial thrombosis. Circulation 2003; 107:26012606.

12 Slotki I: Intravenous iron supplementation in the anaemia of renal and cardiac failure: a double-edged sword? Nephrol Dial Transplant 2005;20:716-723.

13 Agarwal R: Proinflammatory effects of iron sucrose in chronic kidney disease. Kidney Int 2006;69:1259-1263.

14 Agarwal R, Vasavada N, Sachs NG, Chase S: Oxidative stress and renal injury with intravenous iron in patients with chronic kidney disease. Kidney Int 2004;65:2279-2289.

15 Anirban G, Kohli HS, Jha V, Gupta KL, Sakhuja V: The comparative safety of various intravenous iron preparations in chronic kidney disease patients. Ren Fail 2008;30: 629-638.

16 Ganguli A, Kohli HS, Khullar M, Lal Gupta K, Jha V, Sakhuja V: Lipid peroxidation products formation with various intravenous iron preparations in chronic kidney disease. Ren Fail 2009;31:106-110.
17 Maruyama Y, Nakayama M, Yoshimura K, Nakano H, Yamamoto H, Yokoyama K, et al: Effect of repeated intravenous iron administration in haemodialysis patients on serum 8-hydroxy-2'-deoxyguanosine levels. $\mathrm{Ne}$ phrol Dial Transplant 2007;22:1407-1412.

-18 Kartikasari A, Georgiou N, Visseren F, van Kats-Renaud H, van Sweder A, Marx J: Endothelial activation and induction of monocyte adhesion by nontransferrin-bound iron present in human sera. FASEB J 2006;20: 353-355.

19 Rooyakers T, Stroes E, Kooistra M, et al: Ferric saccharate induces oxygen radical stress and endothelial dysfunction in vivo. Eur J Clin Invest 2002;32:S19-S16.

20 Garcia-Fernandez N, Echevarria A, Sanchez-Ibarrola A, Paramo J, Coma-Cannela I: Randomized, clinical trial on acute effects of i.v. iron sucrose during hemodialysis. Nephrology 2010;15:178-183.

21 Reis K, Guz G, Ozdemir H, et al: Intravenous iron therapy as a possible risk factor for atherosclerosis in end stage renal disease. Int Heart J 2005;46:255-264.

22 Zager R: Parenteral iron treatment induces MCP-1 accumulation in plasma, normal kidneys, and in experimental nephropathy. Kidney Int 2005;68:1533-1542.

23 Sonnweber T, Theurl I, Seifert M, et al: Impact of iron treatment on immune effector function and cellular iron status of circulating monocytes in dialysis patients. Nephrol Dial Transplant 2011;26:977-987.

24 Sindrilaru A, Peters T, Wieschalka S, Baican $\mathrm{C}$, et al: An unrestrained proinflammatory M1 macrophage population induced by iron impairs wound healing in humans and mice. J Clin Invest 2011;121:985-997.

25 Shah SV, Alam MG: Role of iron in atherosclerosis. Am J Kidney Dis 2003;41:S80-S83. 